\title{
Synthesis, kinetics of photo-dimerization/photo-cleavage and physical properties of coumarin-containing branched polyurethanes based on polycaprolactones
}

\author{
R. Seoane Rivero ${ }^{1}$, P. Bilbao Solaguren ${ }^{1}$, K. Gondra Zubieta ${ }^{1}$, L. Peponi ${ }^{2}$, A. Marcos-Fernández ${ }^{2 *}$ \\ ${ }^{1}$ Gaiker Centro Tecnológico, Parque Tecnológico Edificio 202, 48170 Zamudio, Spain \\ ${ }^{2}$ Instituto de Ciencia y Tecnología de Polímeros (CSIC), Juan de la Cierva 3, 28006 Madrid, Spain
}

Received 2 July 2015; accepted in revised form 31 August 2015

\begin{abstract}
A series of coumarin-containing branched polyurethanes based on polycaprolactones, hexamethylene diisocyanate and a monohydroxylated coumarin monomer with 5 and $10 \%$ content by weight of coumarin units were successfully prepared. Chain architecture was controlled by combination of polycaprolactone (PCL) triol or tetrol with PCL diol. Terminal coumarin units segregated from the polyurethane matrix as measured by differential scanning calorimetry (DSC). Photo-dimerization with $313 \mathrm{~nm}$ lamps presented an anomalous behavior in two steps with high irreversibility at high conversions. Photo-dimerization/photo-cleavage reactions showed an increase in irreversibility with the increase in cycles. It was demonstrated that conversion measured by Raman spectroscopy gave the same results than conversion measured by ultraviolet (UV) spectroscopy. Photo-dimerization produced an elastomeric material with much better mechanical properties than non-irradiated material as a consequence of the crosslinking produced. Photo-cleavage decreased the mechanical properties and repeated photo-dimerization increased mechanical properties again.
\end{abstract}

Keywords: smart polymers, coumarin, polycaprolactone, polyurethanes

\section{Introduction}

Self-healing polymers [1-4], which are able to autonomously repair damage inflicted on them, are at the forefront of recent developments in materials chemistry and engineering. Some of them can selfrepair by surface contact [5], but most need different external agents, such as heat or light. By heating, for example, a Diels-Alder reaction can take place in elastomeric polymers [6-8]. Light is used to produce reactions in light-sensitive materials such as antracenes [9, 10], coumarins [11], or cinammic acid derivatives $[9,12]$. These light-sensitive materials have been used in shape memory polymers [12], hydrogels [10], surface patterning [13], drug release [14-17], and intraocular lenses [18]. Self-healing at room temperature can be achieved by light expo- sure of the damage if the crack surfaces contain reactive moieties that can react to form new chemical bonds under irradiation. These photo-reactive groups should be part of the polymer structure without compromising the desired properties, which often means a limited content $[19,20]$.

Coumarin molecules can undergo reversible photoinduced reactions; thus, when irradiated at $365 \mathrm{~nm}$ a $[2+2]$ cycloaddition reaction to give rise to a cyclobutane ring takes place, and when irradiated at $254 \mathrm{~nm}$ a photo-cleavage reaction renders the original coumarin structures as shown in Figure 1 [11, 21-23]. Coumarin monomers have been included in the backbone of different types of polymers, including polyethers [21], poly(meth)acrylates [23, 24], polyesters [25] and polyurethanes [19].

\footnotetext{
${ }^{*}$ Corresponding author, e-mail: amarcos@ictp.csic.es

(C) BME-PT
} 


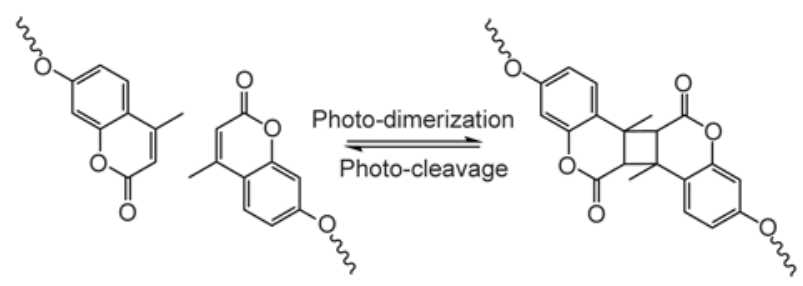

Figure 1. Photo-dimerization/photo-cleavage reactions of coumarin molecules

Polyurethanes are considered excellent materials because of their good physical properties. This is the reason why this material is used in different and numerous applications. Some applications of these materials are biomedical, coating and adhesive applications $[26,27]$. When incorporated in a polyurethane chain, the coumarin monomer was introduced as a chain end [20,28] or as a chain extender [19]. In both cases coumarin monomer was linked to the isocyanate monomer by a polar urethane group, and when introduced as a chain extender, coumarin units were within the hard segments.

In this work we report coumarin-based photo-reactive polyurethanes based on PCL macroglycols, hexamethylene diisocyanate and a monohydroxylated coumarin monomer. PCL macroglycols were chosen because it is well known that polyesters produce polyurethanes with better mechanical properties than polyethers. In addition, PCL polyesters are biodegradable and non-toxic and potentially could be used for biomedical applications. Short PCL were chosen to avoid crystallization as much as possible in order to obtain transparent materials where radiation could penetrate more deeply. Through the right combination of a PCL triol or tetrol with a PCL diol, branched materials with the highest possible molecular weight without reaching gelation could be obtained. In this way, these solu- ble materials could form films and after minimum irradiation, a network could be formed.

\section{Experimental section \\ 2.1. Materials}

PCL900 triol $\left(\mathrm{CAPA}^{\circledR}\right.$ 3091, hydroxyl number $184.10 \mathrm{mgKOH} / \mathrm{g}$, molecular weight $914 \mathrm{~g} / \mathrm{mol}$ ) and PCL1000 tetrol (CAPA ${ }^{\circledR} 4101$, hydroxyl number $224.10 \mathrm{mgKOH} / \mathrm{g}$, molecular weight $1001 \mathrm{~g} / \mathrm{mol}$ ) were a gift from Perstorp (Warrington, UK), and PCL530 (molecular weight $527 \mathrm{~g} / \mathrm{mol}$ ) was supplied by Sigma Aldrich Química S.L (Madrid, Spain). PCLs were vacuum dried at $90{ }^{\circ} \mathrm{C}$ for $3 \mathrm{~h}$ and stored in a desiccator until used.

Resorcinol, ethyl acetoacetate, 2-bromoethanol, stannous octoate and hexamethylene diisocyanate were supplied by Sigma Aldrich Química S.L (Madrid, Spain) and used as received. Concentrated sulphuric acid and potassium carbonate were supplied by Panreac (Barcelona, Spain) and used as received. Dimethylformamide and 1,2-dichloroethane were supplied by Scharlau (Barcelona, Spain) and used as received.

\subsection{Synthesis of 7-hydroxyethoxy-4- methylcoumarin (HEOMC)}

7-hydroxyethoxy-4-methylcoumarin (HEOMC) was prepared as described in literature in two steps [20, 23], as shown in Figure 2.

The characterization of the molecule was made using nuclear magnetic resonance (NMR) analysis.

${ }^{1} \mathrm{H}$ NMR (400 MHz, DMSO-d 6 , ppm): 7.67 (d, 1H, $J=9.6 \mathrm{~Hz}, c), 6.96\left(\mathrm{dd}, 1 \mathrm{H}, J_{1}=9.6 \mathrm{~Hz}, J_{2}=\right.$ $2.8 \mathrm{~Hz}, d), 6.96(\mathrm{~d}, J=2.8 \mathrm{~Hz}, 1 \mathrm{H}, e), 6.19(\mathrm{~d}, J=$ $1.2 \mathrm{~Hz}, 1 \mathrm{H}, a), 4.9$ (s broad, $1 \mathrm{H},-\mathrm{OH}), 4.08$ (t, $J=$ $4.8 \mathrm{~Hz}, 2 \mathrm{H}, k), 3.74(\mathrm{t}, J=4.8 \mathrm{~Hz}, 2 \mathrm{H}, l), 2.38(\mathrm{~d}$,<smiles>[R20]Oc1cccc(O)c1</smiles><smiles>Cc1cc(=O)oc2cc(O)ccc12</smiles>

7-hydroxy-4-methylcoumarin<smiles>Cc1cc(=O)oc2cc(C(C)(Br)Br)ccc12</smiles><smiles>Cc1cc(=O)oc2cc(OC[C@@H](O)CC(C)C)ccc12</smiles>

Figure 2. Synthesis procedure for 7-hydroxyethoxy-4-methylcoumarin (HEOMC) 
$J=1.2 \mathrm{~Hz}, 3 \mathrm{H}, b) .{ }^{13} \mathrm{C}$ NMR $\left(400 \mathrm{MHz}, \mathrm{DMSO}_{-} \mathrm{d}_{6}\right.$, ppm): $161.8(h), 160.2(j), 154.7,153.4(f, i), 126.3$

(c), $113.0(a), 112.4,111.1(d, g), 101.1(e), 70.3$ $(k), 59.4(l), 18.1(b)$.

\subsection{Synthesis of model linear polyurethanes}

In a $25 \mathrm{~mL}$ round-bottomed flask, $1 \mathrm{~g}(1.887 \mathrm{mmol})$ of PCL530, $0.1522 \mathrm{~g}(0.692 \mathrm{mmol})$ of HEOMC and $0.3772 \mathrm{~g}(2.243 \mathrm{mmol})$ of hexamethylene diisocyanate were dissolved in $5 \mathrm{~mL}$ of 1,2-dichloroethane. Two drops of $\mathrm{SnOct}_{2}$ catalyst were added and the stirred solution heated at $80^{\circ} \mathrm{C}$ for $3 \mathrm{~h}$, followed by $24 \mathrm{~h}$ stirring at ambient temperature. The resulting polymeric solution was cast into a Teflon mould and the solvent evaporated at room temperature for $48 \mathrm{~h}$. This polymer had $10 \%$ by weight of coumarin monomer. The models with $5 \%$ by weight of coumarin monomer ( $1 \mathrm{~g}$ of PCL530, $0.0704 \mathrm{~g}$ of HEOMC and $0.3443 \mathrm{~g}$ of HDI) and without coumarin (no HEOMC was added and PCL530 and HDI were added in stoichiometric amounts) were synthesized in the same way.

\subsection{Synthesis of branched polyurethanes}

The branched coumarin-containing polymers were synthesized in the same way as the linear models, that is, one pot synthesis without prepolymerization. In Table 1, the calculated amounts of each reactant for a total of $100 \mathrm{~g}$ of polymer can be found. In the actual synthesis procedure, a total amount of $5 \mathrm{~g}$ of polymer was prepared.

\subsection{Experimental techniques}

Solution NMR spectra were recorded at room temperature in a Varian Unity Plus 400 instrument (Palo Alto, CA, USA) using deuterated dimethylsulfoxide $\left(\mathrm{DMSO}^{-} \mathrm{d}_{6}\right)$ as solvent. Spectra were referenced to the residual solvent signals at $2.50 \mathrm{ppm}$ for proton spectra and $39.5 \mathrm{ppm}$ for carbon spectra.

Irradiations were carried out in a crosslinker supplied by Ultra-Violet Products (Upland, CA, USA) equipped with four sets of $5 \times 8$ watts lamps with emission maxima at $313,354,365$, and $254 \mathrm{~nm}$.

UV experiments were performed in a Perkin Elmer Lambda $35 \mathrm{UV} /$ Vis spectrometer (Waltham, MA, USA). Absorbance of the thin films was measured from 450 to $210 \mathrm{~nm}$.

Raman spectroscopy measurements were carried out by a Renishaw inVia Laser micro-Raman Spectrometer (Wotton-under-Edge, UK). A laser beam with wavelength of $785 \mathrm{~nm}$ served as the excitation light. The testing area on the film was about $1 \mu \mathrm{m}^{2}$. The thermal transitions of the samples were analyzed by DSC on a Mettler Toledo DSC $822 \mathrm{e}$ calorimeter (Schwerzenbach, Switzerland) equipped with a liquid nitrogen accessory. Disc samples cut from films weighing approximately $6 \mathrm{mg}$ were sealed in aluminium pans. Samples were heated, from -90 to $80^{\circ} \mathrm{C}$ at a rate of $10^{\circ} \mathrm{C} \cdot \mathrm{min}^{-1}$, cooled at $10{ }^{\circ} \mathrm{C} \cdot \mathrm{min}^{-1}$ to $-90{ }^{\circ} \mathrm{C}$, maintained for 7 minutes at this temperature and re-heated from -90 to $80^{\circ} \mathrm{C}$ at a rate of $10^{\circ} \mathrm{C} \cdot \mathrm{min}^{-1}$. Crystallization $\left(T_{\mathrm{c}}\right)$ and melting temperatures $\left(M_{\mathrm{p}}\right)$ were taken as the maximum of the exothermic or endothermic transition respectively, and glass transition temperatures $\left(T_{\mathrm{g}}\right)$ were taken as the midpoint of the transition. Melting $\left(\Delta H_{\mathrm{m}}\right)$ and crystallization $\left(\Delta H_{\mathrm{c}}\right)$ enthalpies were calculated by integration of the area of the peaks.

Tensile properties were measured in a MTS Synergie 200 testing machine (Eden Prairie, MN, USA) equipped with a $100 \mathrm{~N}$ load cell. Type 3 dumbbell test pieces (according to ISO 37) were cut from the samples. A cross-head speed of $200 \mathrm{~mm} \cdot \mathrm{min}^{-1}$ was used. Strain was measured from cross-head separation and referred to $10 \mathrm{~mm}$ initial length. A minimum of 3 samples were tested for each material.

\section{Results and discussion \\ 3.1. Synthesis and characterization of coumarin containing polyurethanes}

A series of coumarin end-capped branched polyurethanes having a content of 5 or $10 \%$ by weight of coumarin units were successfully synthesized. Also three linear polymers without coumarin and with 5 or $10 \%$ by weight of coumarin units were prepared as models. The branched polymers were designed to have the maximum possible molecular weight in order to have film forming properties. Starting PCL diol, triol and tetrol had low molecular weight to obtain amorphous or very low crystalline polymers that would be transparent and would allow penetration of UV radiation.

From Carothers equations, when monomers with functionality above 2 are used, gel point can be calculated with the Equation (1):

$$
p=\frac{2}{f_{\text {avg }}}
$$

where $p$ is the conversion at the gel point and $f_{\text {avg }}$ is the average functionality of the reactants. 
To avoid gelation, $f_{\text {avg }}$ should be 2 (only at $100 \%$ conversion a gel would be obtained), and if only a PCL triol or a PCL tetrol are used to build up the branched polymer by reaction with hexamethylenediisocyanate (HDI), an equivalent ratio of $\mathrm{HDI} / \mathrm{PCL}$ triol and HDI/PCL tetrol of $4 / 3$ and 6/4 respectively has to be used. For these HDI/PCL equivalent ratios, the reaction of the free isocyanate groups with the equivalent amount of hydroxyl-coumarin (HEOMC) would produce branched polymers with a coumarin content of 15.1 and $22.6 \%$ by weight for PCL triol and PCL tetrol respectively.

Mixtures of PCL triol or tetrol with short difunctional PCL were necessary to reduce the coumarin content in the final branched polymer. Calculations by using Carothers equations allowed for the determination of the equivalent ratios of PCL triol/PCL diol and PCL tetrol/PCL diol to be reacted with HDI to obtain a final $f_{\text {avg }}=2$ at full conversion, and the appropriate amount of free isocyanate groups to react with $\mathrm{HEOMC}$ giving a final coumarin content of 5 or $10 \%$ by weight in the final branched polymer, as shown in Figure 3 for the polymer based on triol PCL900, diol PCL530, HDI and $5 \mathrm{wt} \%$ HEOMC.

As an example, the equations used for polymer PCL1000+PCL530+HDI+HEOMC5\% are given in the following. Starting from $1 \mathrm{~mol}$ of PCL1000 (molecular weight 1001 , functionality 4 ), to obtain a $5 \mathrm{wt} \%$ of HEOMC in the final polymer we need to combine $x$ mol of PCL530 (molecular weight 527, functionality 2), $y$ mol of HDI (molecular weight 168.2, functionality 2) and $z$ mol of HEOMC (molecular weight 220.2 , functionality 1 ), as shown in Equation (2):

$$
0.05=\frac{220.2 z}{1001 \cdot 1+527 \cdot z+168.2 \cdot y+220.2 \cdot z}
$$

For a stoichiometric reaction, the equivalents of isocyanate groups from HDI must equal the equivalents of hydroxyl groups from PCL1000, PCL530 and HEOMC, see Equation (3):

$2 \cdot y=4 \cdot 1+2 \cdot x+z$

And finally, from Carothers equations for a non-stoichiometric reaction $(r \neq 1)$, to obtain the maximum molecular weight in the reaction between HDI and PCL1000+PCL530, final average functionality should be 2 according to Equation (4):

$2=\frac{2 \cdot(4 \cdot 1+2 \cdot x)}{1+x+y}$

Working out the three equations the unknown amounts in mol for each reactant $(x, y, z)$ are obtained, and from the mol ratio of the reactants the respective weight amounts are calculated.

In the following table, the weight amounts of each reactant, calculated for a total amount of $100 \mathrm{~g}$ of branched polymer are listed.

Branched polymers were prepared in 1,2-dichloroethane by mixing all reactants and using stannous
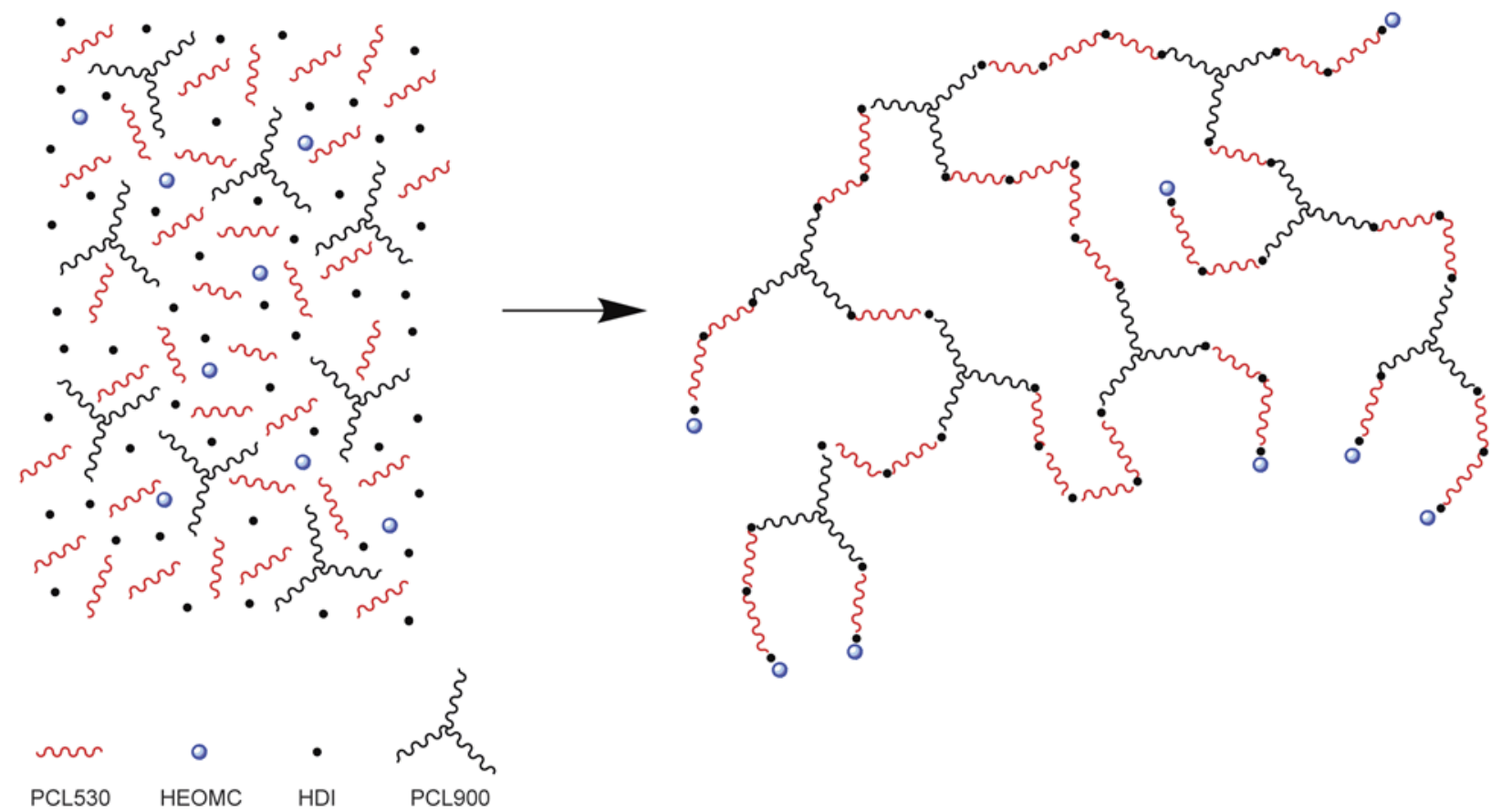

Figure 3. Reaction scheme for the preparation of the branched polyurethanes 
Table 1. Amounts of reactants $[\mathrm{g}]$ in the synthesis of coumarin containing branched polyurethanes (calculated for $100 \mathrm{~g}$ of final polymer)

\begin{tabular}{|c|c|c|c|c|c|}
\hline POLYURETHANE & PCL900 triol & PCL1000 tetrol & PCL530 diol & HDI & HEOMC \\
\hline PCL900+PCL530+HDI+HEOMC 5\% & 20.43 & - & 50.76 & 23.81 & 5.00 \\
\hline PCL900+PCL530+HDI+HEOMC 10\% & 40.87 & - & 25.69 & 23.45 & 10.00 \\
\hline PCL1000+PCL530+HDI+HEOMC 5\% & - & 11.35 & 59.09 & 24.56 & 5.00 \\
\hline PCL1000+PCL530+HDI+HEOMC10\% & - & 22.70 & 42.35 & 24.94 & 10.00 \\
\hline
\end{tabular}

octoate as catalyst. Films were obtained by casting directly the solution onto a Teflon mold and solvent evaporation at ambient temperature.

Similar branched polymers have been described in literature with poly(ethylene glycol) as the soft segment, a HDI trimer as the polyisocyanate and HEOMC as the coumarin monomer [20], but in that case the polymer structure was not controlled. Although not explained in that work, in a following paper by these authors [19] it was explained that some gelation occurred during synthesis as a consequence of the actual composition of the HDI trimer, in fact a mixture of compounds with some of them of higher functionality $(4,5$, etc). With our synthesis procedure, no gel appeared and the final branched polymers were completely soluble with a molecular weight high enough to form films.

Thermal properties of the branched polymers as determined by DSC can be found in Table 2. The thermal properties of the linear models have been included for comparison.

In the first run from ambient temperature, an endothermic transition with several maxima was obtained, demonstrating that PCL530 chains can crystallize and, in principle, the endotermic peak could be related to PCL crystals melting. However, the max- imum at higher temperature for the model linear polymer PCL530+HDI (with no coumarin) is at approximately $51^{\circ} \mathrm{C}$. And when HEOMC is introduced, the maximum at higher temperature is close or above $60{ }^{\circ} \mathrm{C}$, that is, at significantly higher temperature. This result is unexpected, especially for branched polymers because branching points should introduce irregularities that should produce a material with lower crystallinity and smaller crystals with lower melting point. Besides, when HEOMC content increased, the relative area of the endotherm at the higher temperature side and the temperature at the higher temperature maximum increased as it is shown in Figure 4. From these results, it was deduced that coumarin end-groups were able to segregate in an ordered phase. Data from second heating run were consistent with this deduction (see Figure 5). After PCL segments glass transition, an exothermic crystallization peak due to PCL segments crystallization appeared, followed by a single endothermic peak due to PCL segments melting ending at $53{ }^{\circ} \mathrm{C}$ in the case of the linear polymer PCL530+HDI. For the polymers with coumarin end-groups, a melting endotherm with a maximum and a shoulder at higher temperature was observed for polymers PCL900+ PCL530+HDI+HEOMC 5\% and PCL1000+PCL530+

Table 2. Thermal properties of coumarin containing branched polyurethanes

\begin{tabular}{|c|c|c|c|c|c|c|c|}
\hline \multirow[b]{2}{*}{ POLYURETHANE } & \multicolumn{2}{|c|}{ First scan } & \multicolumn{5}{|c|}{ Second scan } \\
\hline & $\begin{array}{c}M_{\mathrm{p}} \\
{\left[{ }^{\circ} \mathbf{C}\right]}\end{array}$ & $\begin{array}{l}\Delta H_{\mathrm{m}} \\
{[\mathrm{J} / \mathrm{g}]}\end{array}$ & $\begin{array}{c}T_{\mathrm{g}} \\
{\left[{ }^{\circ} \mathbf{C}\right]} \\
\end{array}$ & $\begin{array}{c}T_{\mathrm{c}} \\
{\left[{ }^{\circ} \mathrm{C}\right]} \\
\end{array}$ & $\begin{array}{c}\Delta \boldsymbol{H}_{\mathrm{c}} \\
{[\mathrm{J} / \mathrm{g}]} \\
\end{array}$ & $\begin{array}{c}M_{\mathbf{p}} \\
{\left[{ }^{\circ} \mathbf{C}\right]} \\
\end{array}$ & $\begin{array}{l}\Delta H_{\mathrm{m}} \\
{[\mathbf{J} / \mathbf{g}]}\end{array}$ \\
\hline PCL530+HDI & $\begin{array}{l}36.5 \\
45.7 \\
50.9 \\
\end{array}$ & 17.69 & -41.5 & 2.9 & -15.94 & 36.6 & 16.61 \\
\hline PCL530+HDI+HEOMC 5\% & $\begin{array}{l}43.9 \\
58.8 \\
\end{array}$ & 8.99 & -45.6 & -6.8 & -4.79 & $\begin{array}{l}25.3 \\
50^{*}\end{array}$ & 15.08 \\
\hline PCL530+HDI+HEOMC 10\% & $\begin{array}{l}38.9 \\
57.3 \\
\end{array}$ & 4.47 & -47.7 & -5.7 & -2.29 & $\begin{array}{l}17 \\
63.3 \\
\end{array}$ & 5.11 \\
\hline PCL900+PCL530+HDI+HEOMC 5\% & $\begin{array}{l}48.0 \\
61.9 \\
\end{array}$ & 4.14 & -41.9 & 3.2 & -2.81 & $\begin{array}{l}31.1 \\
51^{*}\end{array}$ & 6.43 \\
\hline PCL900+PCL530+HDI+HEOMC 10\% & $\begin{array}{l}48.9 \\
65.6 \\
\end{array}$ & 3.94 & -36.8 & 9.0 & -0.49 & 52.4 & 1.83 \\
\hline PCL1000+PCL530 +HDI+HEOMC 5\% & $\begin{array}{l}46.3 \\
61.0 \\
\end{array}$ & 4.09 & -41.3 & 2.9 & -4.17 & $\begin{array}{l}31.2 \\
51^{*}\end{array}$ & 5.75 \\
\hline PCL1000+PCL530+HDI+HEOMC 10\% & $\begin{array}{l}47.7 \\
66.7 \\
\end{array}$ & 2.49 & -35.5 & 22.5 & -1.14 & 55.5 & 1.47 \\
\hline
\end{tabular}

*Shoulder. Temperature is approximate. 


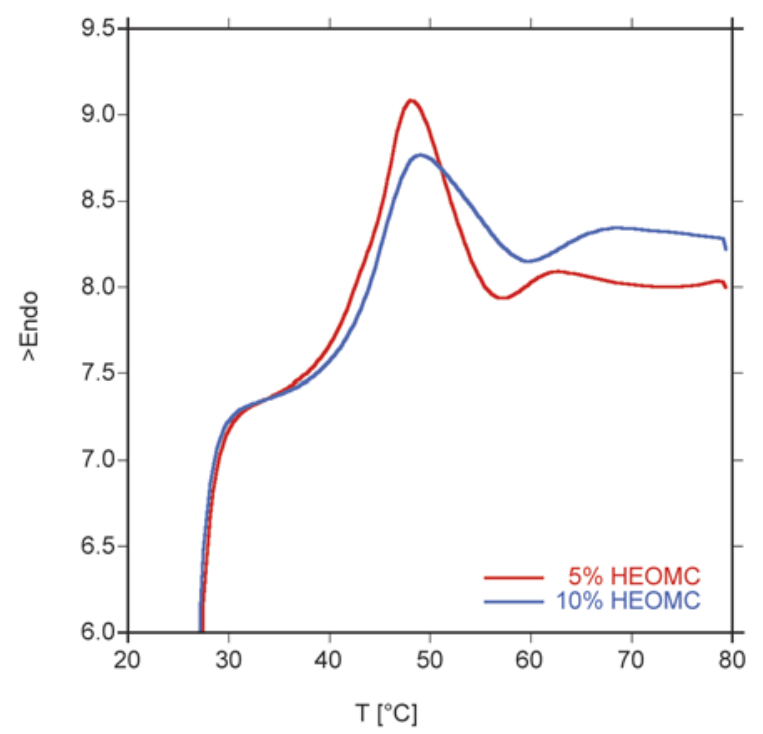

Figure 4. First heating curves for the polymers PCL900+ PCL530+HDI+HEOMC 5\% (red line) and PCL900+PCL530+HDI+HEOMC 10\% (blue line)

HDI+HEOMC $5 \%$, the maximum at lower temperatures due to PCL segments melting and the shoulder at higher temperatures assigned to coumarin end-groups melting. For polymers PCL900+ PCL530+HDI+HEOM 10\% and PCL1000+PCL530+ HDI+HEOMC $10 \%$ a single peak was obtained with the peak end located at $74.6^{\circ} \mathrm{C}$ thus both melting endotherms (PCL and coumarin end-groups melting) are merged in a single peak (see Figure 5).

A similar peak was found in polymers prepared from PEG400-diol+HDI-trimer+HEOMC [20], with the maximum at $58.6{ }^{\circ} \mathrm{C}$. In that work the endothermic peak was assigned to hard segment glass transition, although a glass transition should show a change in heat capacity and the authors found a broad endotherm as the ones shown in Figures 2 and 3. As already explained above, it seems more appropriate to assign the endotherm at higher temperature to the ordering of the coumarin end units.

Enthalpy values of the melting peaks $\left(\Delta H_{\mathrm{m}}\right)$ are very low. The highest value, as expected, is for the linear model polymer without coumarin (PCL530+ HDI). Taking into account that only PCL530 segments can crystallize, after correction for the PCL530 content on the polymer ( $75.8 \%$ by weight) and taking $148.24 \mathrm{~J} / \mathrm{g}$ as the value for the crystallization heat for a $100 \%$ crystallized pure high molecular weight PCL [29], only $15.7 \mathrm{wt} \%$ of the PCL530 (12 wt\% respect to the total polymer weight) is able to crystallize. For the branched polyurethanes, the percentage of crystalline PCL530 is even lower. Although it

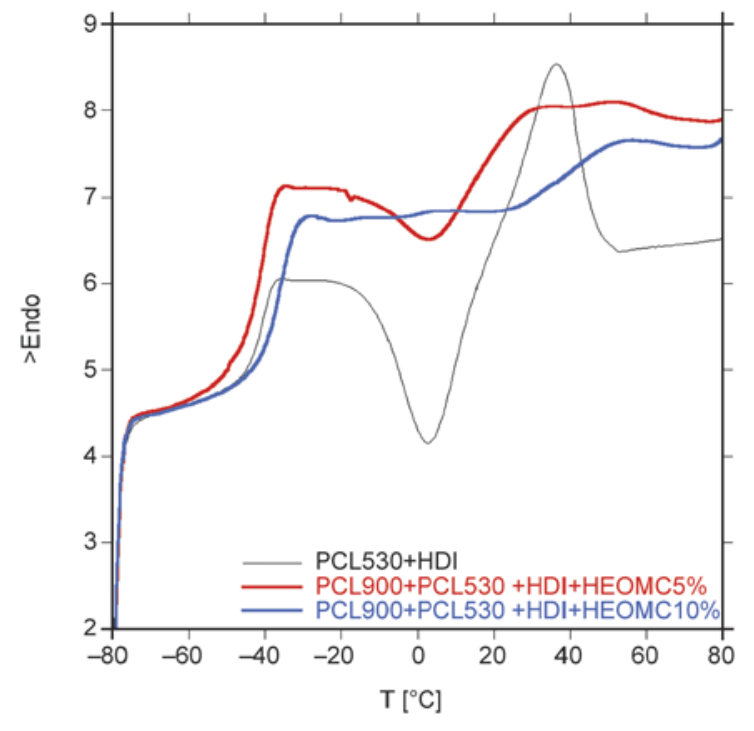

Figure 5. Second heating curves for the polymers PCL530+ HDI (black line), PCL900+PCL530+HDI+ HEOMC 5\% (red line) and PCL900+PCL530+ HDI+HEOMC 10\% (blue line)

cannot be calculated because the endotherm is the sum of PCL segments plus coumarin-end groups melting, the weight percentage will be even lower than for the model linear polymers, thus branched polyurethanes are almost completely amorphous. When HEOMC content is increased, the weight content of PCL530 diol in the polymer is decreased, and the enthalpy due to PCL530 segment crystallinity must decrease. However, if the enthalpy values are corrected for the PCL530 content on the polymer, it is found that despite the expected increase in the melting enthalpy due to the increase in coumarin-end groups melting, the overall value of the enthalpy decreases, thus the PCL530 segments crystallinity is decreased when HEOMC content is increased. When branched polymers based on triol PCL900 or tetrol PCL1000 are compared, for the same HEOMC content and after correcting for the PCL530 content on the polymer, it is observed that crystallinty is slightly lower for the polymers based on tetrol PCL1000.

\subsection{Photo-dimerization/photo-cleavage kinetics in thin films}

Three different set of lamps were tested for the photopolymerization of coumarin-based polymers. In Figure 6, the emission spectra of the lamps are shown. For lamp with maximum at $313 \mathrm{~nm}$, emission starts at $270 \mathrm{~nm}$; for lamp with maximum at $354 \mathrm{~nm}$, emis- 


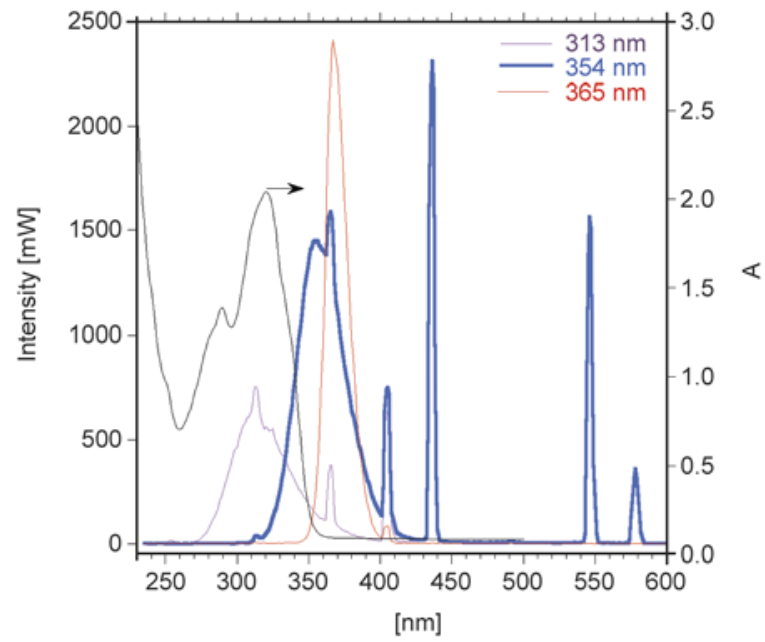

Figure 6. Emission spectra of the three different lamps used for photo-dimerization. Absorption spectrum of the polymer PCL530+HDI+HEOMC 10\% (black line) has also been included.

sion starts at $310 \mathrm{~nm}$; and for lamp with maximum at $365 \mathrm{~nm}$, emission starts at $350 \mathrm{~nm}$.

Photo-dimerization was followed for a film of polymer PCL530+HDI+HEOMC 10\%. Film was cast from a chloroform solution of the polymer onto a side of a quartz cuvette. Final thickness of the film was approximately 2 microns.

In Figure 6, the absorption spectra of the film can be seen. Absorption of coumarin shows a $\pi-\pi^{*}$ transition between 260 and $300 \mathrm{~nm}$ attributed to electrons of the conjugated benzene nucleus and another $\pi-\pi^{*}$ transition between 310 and $340 \mathrm{~nm}$ assigned to the pyrone nucleus [20, 28].

Emission spectrum of the $313 \mathrm{~nm}$ lamp was almost coincident, whereas emission spectrum of the $354 \mathrm{~nm}$ lamp was coincident in the range $310-350 \mathrm{~nm}$ and emission spectrum of the $365 \mathrm{~nm}$ lamp barely overlapped at the very end of the absorption band of coumarin. From this graph, it was expected that lamp $313 \mathrm{~nm}$ would be more efficient than lamp $354 \mathrm{~nm}$, and lamp $365 \mathrm{~nm}$ would have a very poor efficiency. UV absorption in the maximum at approximately $320 \mathrm{~nm}$ was measured at different irradiation times, as seen on Figure 7. The absorption decreased because of the dimerization of the coumarin double bonds to form cyclobutane rings, which destroyed the conjugated $\pi$-system.

Conversion (or dimerization degree) was calculated from Equation (5):

Conversion $=1-\frac{A_{\mathrm{t}}}{A_{0}}$

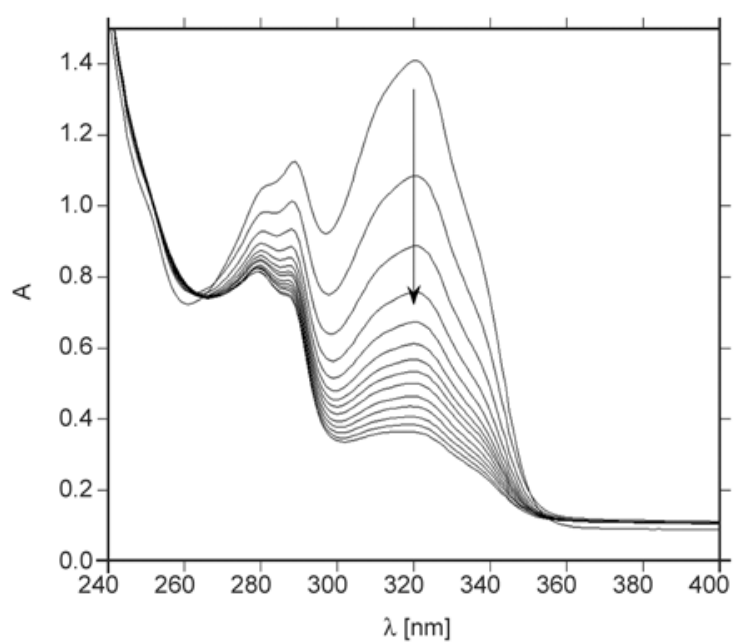

Figure 7. UV spectra of polymer PCL530+HDI+ HEOMC $10 \%$ when irradiated at different times

where $A_{\mathrm{t}}$ and $A_{0}$ denote the absorbance at $320 \mathrm{~nm}$ at time $t$ and 0 respectively after subtraction of the baseline value at $400 \mathrm{~nm}$. In Figure 8, the conversion for polymer PCL530+HDI+HEOMC 10\% when irradiated at different times with lamp $313 \mathrm{~nm}$ can be seen.

At the beginning, dimerization was very fast, reaching 35-40\% conversion within the first minute. In the following 15 minutes, conversion reached a plateau and did not change significantly with irradiation time, and afterwards, conversion increased steadily with irradiation time up to approximately $75-80 \%$ conversion at 140 minutes. In the graph, four different samples were irradiated, showing a quite good repeata-

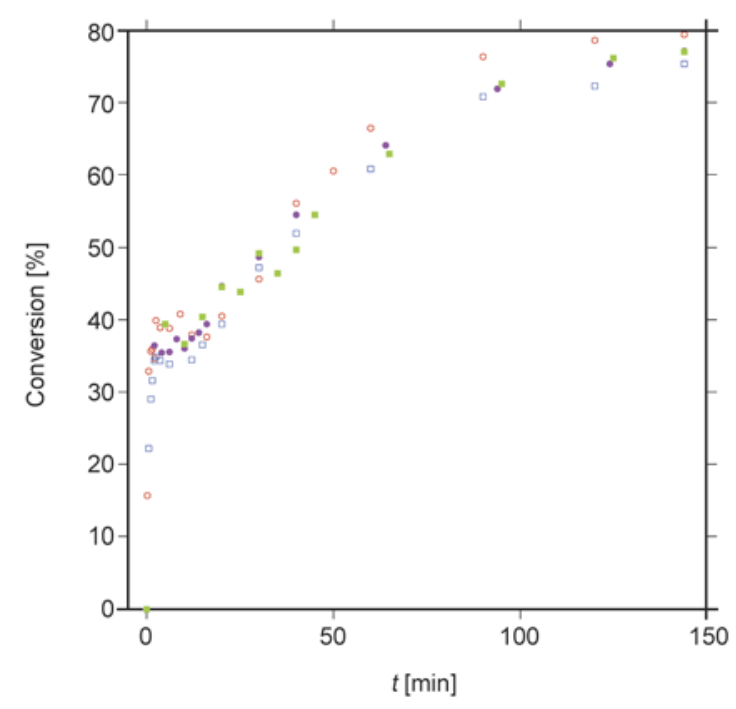

Figure 8. Conversion for polymer PCL530+HDI+ HEOMC $10 \%$ when irradiated at different times with lamp $313 \mathrm{~nm}$, for 4 different dimerization reactions 
bility. This kinetic profile was unexpected, and it has not been reported in literature.

When the polymer film was irradiated with 354 or $365 \mathrm{~nm}$ lamps, conversion increased continuously with irradiation time until a plateau was reached, at approximately $85-90 \%$ conversion (Figure 9). This ultimate conversion is similar to the conversion found in other methylcoumarin containing polymers, for which maximum conversions reported are $77.5 \%$ [20], 81.5\% [22] and approximately $80 \%$ [11]. Repeatability in conversion was as good as for the curves in Figure 6. Conversion rate was much slower for irradiation with the $365 \mathrm{~nm}$ lamp, but the shape of the dimerization curves was similar. When compared with the curve for irradiation with the $313 \mathrm{~nm}$ lamp it is clear that although within the first minute this lamp produced higher conversion, at longer times, lamp $354 \mathrm{~nm}$ produced higher conversions. With lamp $354 \mathrm{~nm}$ the plateau was reached at approximately 30 minutes, whereas for lamp $365 \mathrm{~nm}$ the plateau value was reached at approximately 20 hours. Photo-cleavage of the dimerized films was carried out with the $254 \mathrm{~nm}$ lamps. These lamps presented a narrow irradiation band from 251 to $257 \mathrm{~nm}$ with a maximum at $254 \mathrm{~nm}$ and some other similar small narrow bands with maxima at 313 and $365 \mathrm{~nm}$. Test on dimerized samples proved that 15 minutes irradiation with lamp $254 \mathrm{~nm}$ was enough to produce almost complete photo-cleavage.

Samples of polymer PCL530+HDI+HEOMC 10\% where irradiated for certain times with lamp $313 \mathrm{~nm}$

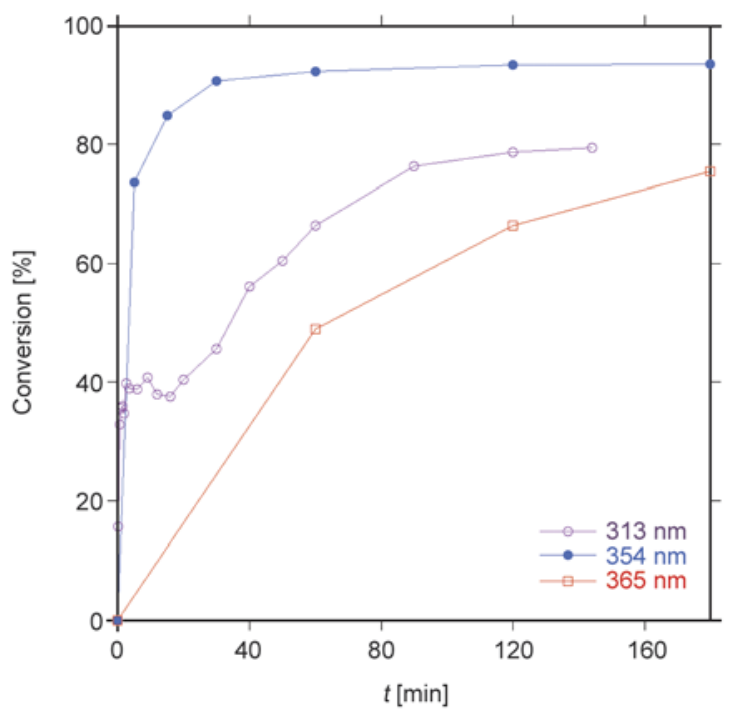

Figure 9. Conversion for polymer PCL530+HDI+ HEOMC $10 \%$ when irradiated at different times with lamp $313 \mathrm{~nm}$ (purple), lamp $354 \mathrm{~nm}$ (blue) or lamp $365 \mathrm{~nm}$ (red)

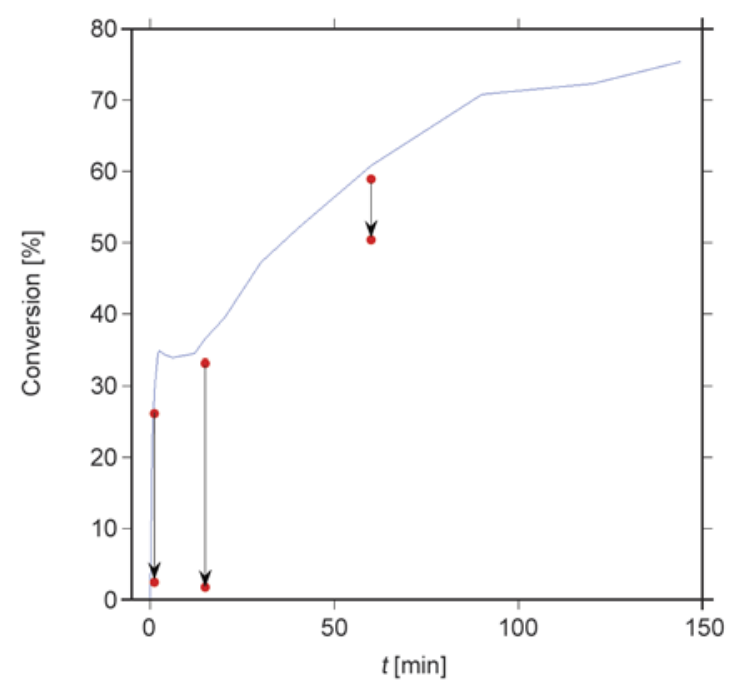

Figure 10. Photo-dimerization for polymer PCL530+HDI+ HEOMC10\% when irradiated at different times with lamp $313 \mathrm{~nm}$ and corresponding photocleavage with $354 \mathrm{~nm}$ lamp for 15 minutes. Line shows the complete photo-dimerization curve.

and after dimerization, where irradiated with lamp $254 \mathrm{~nm}$ for photo-cleavage. In Figure 10, the results are shown. It can be seen that when dimerized for up to 15 minutes, that is, during the initial fast growing part of the curve and the plateau between 1 and 15 minutes, photo-cleavage was almost complete, but for higher irradiation time photo-cleavage was strongly reduced, and for 60 minutes irradiation time photo-cleavage was only a $10 \%$.

For 354 and $365 \mathrm{~nm}$ lamps, photo-cleavage was more efficient at high irradiation times. In Figure 11 for example, for irradiation with $354 \mathrm{~nm}$ lamp, it can be found that photo-cleavage had approximately the same efficiency at any dimerization conversion but photo-cleavage was not complete and always a dimerized material (approximately 20-25\%) remained. It has been shown extensively by other authors that photo-cleavage is never complete and is attributed to a dynamic equilibrium between photo-dimerization and photo-cleavage [11, 19-22, 25]. It was also pointed out that prolonged exposure to $254 \mathrm{~nm}$ light would result in an irreversible structure [20]. For $354 \mathrm{~nm}$ irradiation lamp it seems that the irreversibility reached a fairly constant value (20-25\% dimerization) irrespective of photo-dimerization time, whereas for $313 \mathrm{~nm}$ lamp, irradiation time was critical respect to irradiation time, and long times led to higher irreversibility. It could be deduced that irreversibility is produced mainly by irradiation at wavelengths below $320 \mathrm{~nm}$, that probably leads to irreversible structures. 


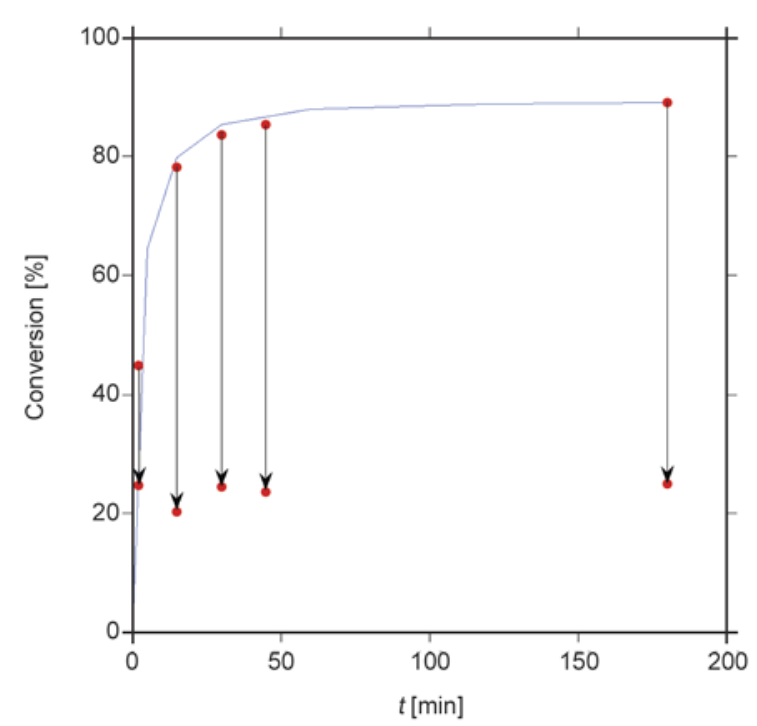

Figure 11. Photo-dimerization for polymer PCL530+HDI+ HEOMC $10 \%$ when irradiated at different times with lamp $354 \mathrm{~nm}$ and corresponding photo-cleavages with lamp $354 \mathrm{~nm}$ for 15 minutes. Line shows the complete photo-dimerization curve.

Branched polymers were photo-dimerized and photocleaved with the 354 and $254 \mathrm{~nm}$ lamps respectively. Up to nine cycles were recorded and the curves were similar for all these polymers. In Figure 12, the cycles for polymer PCL900+PCL530+HDI+ HEOMC $10 \%$ are shown as an example. As it can be seen, the photo-dimerization efficiency slightly decreased and photo-cleavage efficiency was even more reduced from cycle to cycle, showing that irreversibility increased with the number of cycles. It can

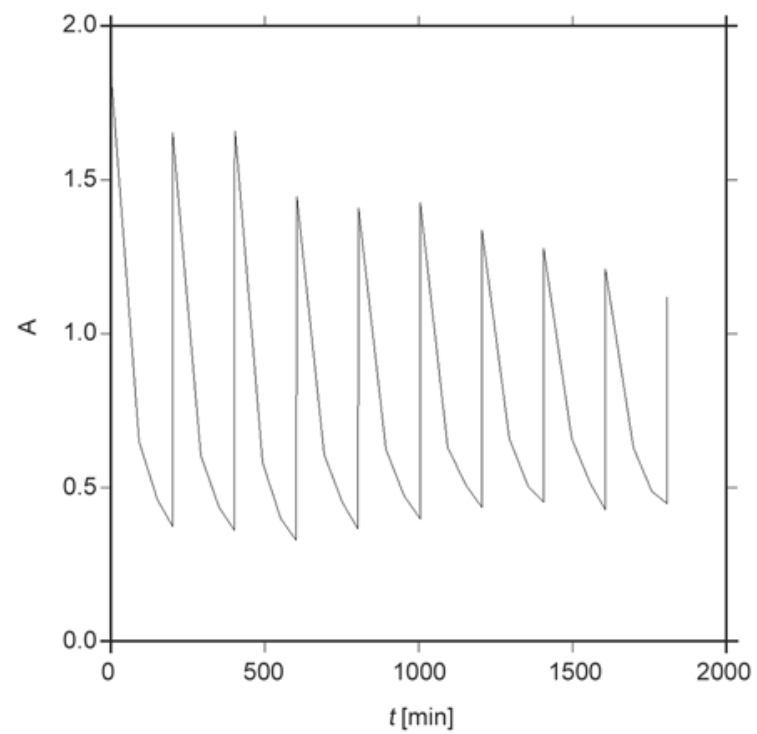

Figure 12. Photo-dimerization and photo-cleavage cycles for polymer PCL900+PCL530+HDI+HEOMC 10\% when irradiated for $200 \mathrm{~min}$ at $354 \mathrm{~nm}$ and for 1 minute at $254 \mathrm{~nm}$ be noted that the loss of efficiency is quite significant for photo-cleavage and it is much lower for photodimerization, as already observed by other authors [21].

\subsection{Photo-dimerization/photo-cleavage kinetics in thick films}

UV spectra were saturated in thick films and Raman spectroscopy was used for measuring photo-dimerization/photo-cleavage conversion, as already reported by other researchers [20]. Raman spectra for polymer PCL530+HDI and polymer PCL530+ HDI+HEOMC $10 \%$ before irradiation and after irradiation at $354 \mathrm{~nm}$ are represented in Figure 13. As it can be seen, the bands related to coumarin units decreased after irradiation at $354 \mathrm{~nm}$. Quantification was done by normalizing the height of the peak related to the coumarin double bond at $1614 \mathrm{~cm}^{-1}$ and the height of the peak at $1441 \mathrm{~cm}^{-1}$ related to methylene groups as shown in Figure 14 for non irradiated PCL530+HDI+HEOMC 10\%.

Photo-dimerization kinetics was measured simultaneously by UV and by Raman in a thin film in order

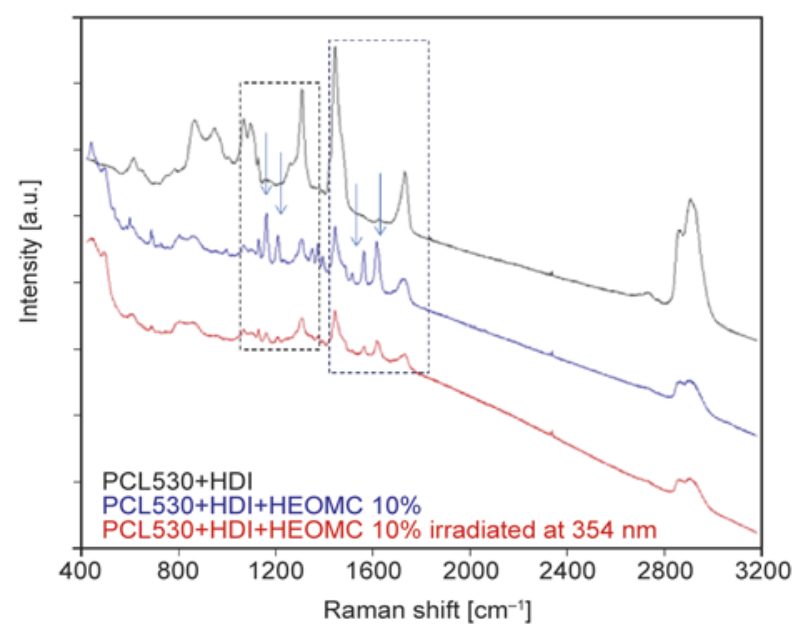

Figure 13. Raman spectrum of PCL530+HDI (black line), non-irradiated PCL530+HDI+HEOMC 10\% (blue line) and PCL530+HDI+HEOMC 10\% irradiated at $354 \mathrm{~nm}$ (red line)

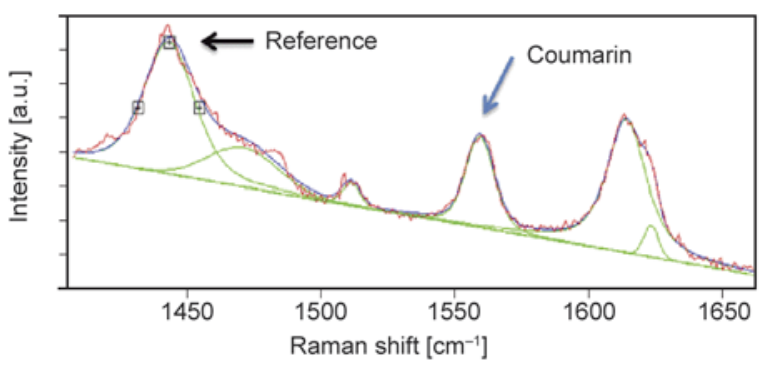

Figure 14. Raman bands used for conversion calculation 


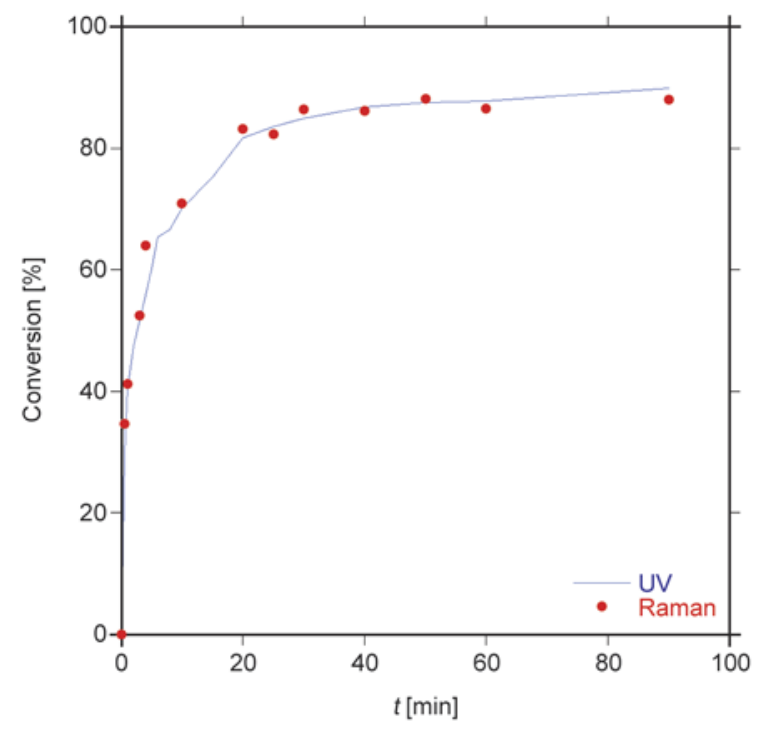

Figure 15. UV versus Raman conversion for polymer PCL530+ HDI+HEOMC 10\%

to compare the data obtained by both techniques. As shown in Figure 15, despite the slight scattering of the Raman data, results are similar demonstrating that Raman can be used to calculate the conversion in thick films.

Raman spectra for the branched polymers (not shown) were very similar to spectra for the linear models. For the thick films prepared to measure mechanical properties Raman was used to calculate conversion.

\subsection{Mechanical properties}

Mechanical properties of linear polymers PCL530+ HDI $5 \%$ and $10 \%$ could not be measured because its films were soft and too weak due to the limited growth of the linear chains. Non irradiated branched coumarin containing polyurethanes were weak and very soft. After irradiation at $354 \mathrm{~nm}$, crosslinking produced by coumarin photo-dimerization increased their properties and a soft rubbery material was finally obtained. In Table 3, the values for tensile stress and strain to failure for films of approxi- mately 150 microns thickness of non irradiated polymers and for the polymers irradiated for 300 minutes at $354 \mathrm{~nm}$ are listed. Conversion measured by Raman after 300 minutes at $354 \mathrm{~nm}$ was approximately $70 \%$ for all the polymers.

When the monomers are reacted, PCL530 and HDI increase the chain length and HEOMC terminates the chains, and when coumarin end-groups photo-dimerize they link two different chains but do not introduce a crosslink point. Therefore, the only polyfunctionality points introduced in the final photo-crosslinked polymer come from the PCL triol or the PCL tetrol. From the data on Table 1 and supposing full conversion of the reactants during the synthesis of the branched polyurethanes and full conversion of the coumarin units during photo-dimerization, a maximum theoretical crosslink density (in moles of crosslink points $\cdot 10^{4} /$ grams of polymer) can be calculated. The calculations give the following order of crosslink density for the polymers:

$$
\begin{aligned}
& \text { PCL1000+PCL530+HDI+HEOMC 5\% (1.13)< } \\
& \text { PCL900+PCL530+HDI+HEOMC 5\% (2.23) } \\
& \text { PCL1000+PCL530+HDI+HEOMC 10\% (2.27)< } \\
& \text { PCL900+PCL530+HDI+HEOMC 10\% (4.47) }
\end{aligned}
$$

From the properties measured, it is clear that tetrafunctional (PCL1000) crosslinks gave better mechanical properties than trifunctional (PCL900) crosslinks for the same crosslink density. And as expected, for the same functionality of the crosslinks, when coumarin content increased the crosslink density increased and the mechanical properties increased. Not much information is found in literature on the mechanical properties of coumarin-containing polyurethanes. For an irradiated polymer composed of PEG400-diol+HDI-trimer+HEOMC with content of $20 \%$ by weight of HEOMC, tensile strength and strain were approximately $2.25 \mathrm{MPa}$ and $140 \%$ respectively [20]; and for irradiated polymers composed of PEG800-diol+IPDI+Coumarine-diol with

Table 3. Mechanical properties of the non-irradiated and irradiated at $354 \mathrm{~nm}$ for 300 minutes branched polyurethanes

\begin{tabular}{|l|c|}
\hline \multicolumn{1}{|c|}{ Polyurethane } & $\begin{array}{c}\text { Stress } \\
{[\mathbf{M P a}]}\end{array}$ \\
\hline PCL900+PCL530+HDI+HEOMC 5\% non-irradiated & $\begin{array}{c}\text { Strain } \\
{[\%]}\end{array}$ \\
\hline PCL900+PCL530+HDI+HEOMC 5\% irradiated & $0.92 \pm 0.12$ \\
\hline PCL900+PCL530+HDI+HEOMC 10\% non-irradiated & $2.3 \pm 0.3$ \\
\hline PCL900+PCL530+HDI+HEOMC 10\% irradiated & $1.8 \pm 0.2$ \\
\hline PCL1000+PCL530+HDI+HEOMC 5\% non-irradiated & $4.9 \pm 0.5$ \\
\hline PCL1000+PCL530+HDI+HEOMC 5\% irradiated & $110 \pm 30$ \\
\hline PCL1000+PCL530+HDI+HEOMC 10\% non-irradiated & $640 \pm 110$ \\
\hline PCL1000+PCL530+HDI+HEOMC 10\% irradiated & $69 \pm 8.11$ \\
\hline
\end{tabular}




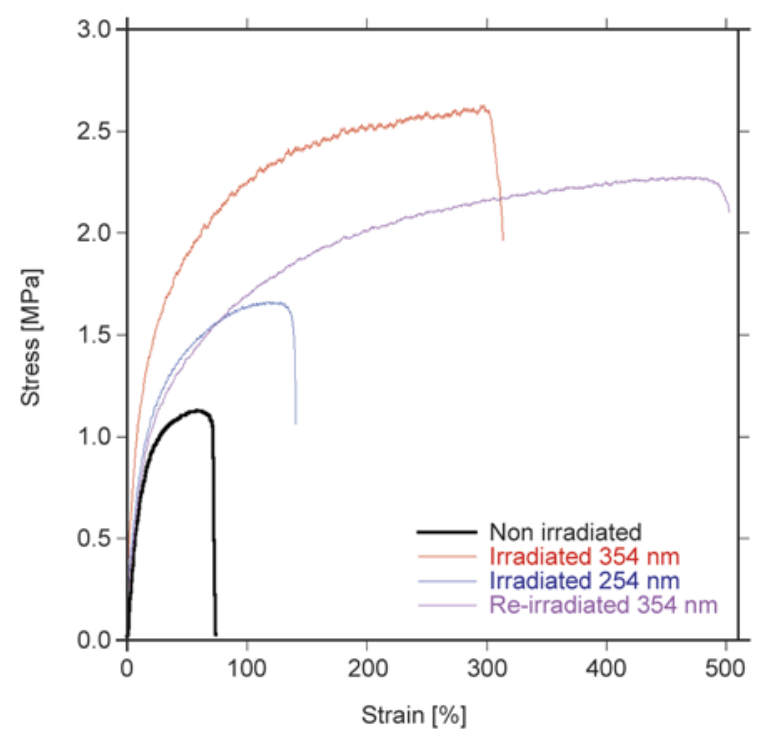

Figure 16. Stress-strain curves for polymer PCL1000+ PCL530+HDI+HEOMC 5\% non-irradiated (black line), irradiated at $354 \mathrm{~nm}$ (red line), irradiated at $354 \mathrm{~nm}+254 \mathrm{~nm}$ (blue line) and $354 \mathrm{~nm}+$ $254 \mathrm{~nm}+354 \mathrm{~nm}$ (purple line)

5.5 and $13 \%$ by weight of coumarin component, with 86 and $94 \%$ of dimerization conversion respectively, values for tensile strength and strain were approximately $1.2 \mathrm{MPa}$ and $650 \%$ and $3.6 \mathrm{MPa}$ and $235 \%$ respectively [19]. Data on Table 3 demonstrate that PCL based materials, despite having lower coumarin content and/or lower conversion and therefore lower crosslink density, after irradiation produce polyurethanes with better mechanical properties than coumarin-containing materials based on PEG.

For all the irradiated branched materials, when irradiated at $254 \mathrm{~nm}$ for 12 minutes mechanical properties decreased as a consequence of photo-cleavage of coumarin units, which decreased the crosslink density of the material. Re-irradiation at $354 \mathrm{~nm}$ for $150 \mathrm{~min}$ utes increased again the crosslink density by photodimerization of coumarin units and mechanical properties recovered, as it can be seen in Figure 16 for the polymer PCL1000+PCL530+HDI+ HEOMC 5\%.

\section{Conclusions}

A series of branched polyurethanes based on PCL with a content of 5 and $10 \%$ by weight of terminal coumarin units were successfully prepared. A mixture of short PCL triol or tetrol with a short PCL diol in the appropriate amounts was necessary to control the molecular architecture, to obtain the maximum possible molecular weight and to avoid gelation during synthesis.
The obtained branched polyurethanes presented low PCL crystallinity and segregation of the coumarin terminal units as showed by DSC measurements. Photo-dimerization curve when irradiation was done with $313 \mathrm{~nm}$ lamps presented 2 distinct steps, the first one with a very fast rate and good yield for photocleavage and the second one with a slower rate and a very strong irreversibility respect to photo-cleavage. Optimum photo-dimerization was achieved when irradiation was done with $354 \mathrm{~nm}$ lamps, although some irreversibility for photo-cleavage was always present and increased with the increase on photo-dimerization/photo-cleavage cycles.

It was demonstrated that Raman spectroscopy gave the same conversion results as UV spectroscopy, and it was used to calculate conversion in thick films.

Mechanical properties of the crosslinked films by photo-dimerization were better than the properties of comparable photo-dimerized polyurethanes found in literature. Photo-cleavage decreased the mechanical properties as a consequence of the decrease in crosslinks and re-photo-dimerization increased again the properties by restoration of the crosslinks.

\section{Acknowledgements}

The authors would like to thank the Ministry of Economy and Competitiveness (MINECO) for the financial support of this work within the framework of the Plan Nacional de I+D+I through the research projects MAT2011-25513, MAT2013-48059-C2 and MAT2014-52644-R and the INNPACTO project IPT-2012-0324-420000. Also, this work has been supported by programme Technology Centres Foundation Iñaki Goenaga.

\section{References}

[1] Guimard N. K., Oehlenschlaeger K. K., Zhou J., Hilf S. F., Schmidt G., Barner-Kowollik C.: Current trends in the field of self-healing materials. Macromolecular Chemistry and Physics, 213, 131-143 (2012). DOI: $10.1002 / \mathrm{macp} .201100442$

[2] Binder W.: Self-healing polymers: From principles to applications. Wiley-VCH, Weinheim (2013).

[3] Billiet S., Hillewaere X. K., Teixeira R. F. A., du Prez F. E.: Chemistry of crosslinking processes for self-healing polymers. Macromolecular Rapid Communications, 34, 290-309 (2013). DOI: $10.1002 /$ marc.201200689

[4] Zhang M. Q., Rong M. Z.: Intrinsic self-healing of covalent polymers through bond reconnection towards strength restoration. Polymer Chemistry, 4, 4878-4884 (2013).

DOI: $10.1039 / \mathrm{C} 3 \mathrm{PY} 00005 \mathrm{~B}$ 
[5] Rekondo A., Martin R., de Luzuriaga A. R., Cabañero G., Grande H. J., Odriozola I.: Catalyst-free room-temperature self-healing elastomers based on aromatic disulfide metathesis. Materials Horizons, 1, 237-240 (2014). DOI: $10.1039 / \mathrm{c} 3 \mathrm{mh} 00061 \mathrm{c}$

[6] Pratama P. A., Sharifi M., Peterson A. M., Palmese G. R.: Room temperature self-healing thermoset based on the Diels-Alder reaction. ACS Applied Materials and Interfaces, 5, 12425-12431 (2013).

DOI: $10.1021 / \mathrm{am} 403459 \mathrm{e}$

[7] Liu Y-L., Chuo T-W.: Self-healing polymers based on thermally reversible Diels-Alder chemistry. Polymer Chemistry, 4, 2194-2205 (2013).

DOI: $10.1039 / \mathrm{c} 2$ py20957h

[8] Pratama P. A., Peterson A. M., Palmese G. R.: Diffusion and reaction phenomena in solution-based healing of polymer coatings using the Diels-Alder reaction. Macromolecular Chemistry and Physics, 213, 173-181 (2012). DOI: 10.1002/macp.201100407

[9] Bergman S. D., Wudl F.: Mendable polymers. Journal of Materials Chemistry, 18, 41-62 (2008).

DOI: $10.1039 / \mathrm{b} 713953 \mathrm{p}$

[10] Zheng Y., Micic M., Mello S. V., Mabrouki M., Andreopoulos F. M., Konka V., Pham S. M., Leblanc R. M.: PEG-based hydrogel synthesis via the photodimerization of anthracene groups. Macromolecules, 35, 52285234 (2002).

DOI: $10.1021 / \mathrm{ma} 012263 \mathrm{z}$

[11] Trenor S. R., Shultz A. R., Love B. J., Long T. E.: Coumarins in polymers: From light harvesting to photocross-linkable tissue scaffolds. Chemical Reviews, 104, 3059-3077 (2004).

DOI: $10.1021 / \mathrm{cr} 030037 \mathrm{c}$

[12] Wu L., Jin C., Sun X.: Synthesis, properties, and lightinduced shape memory effect of multiblock polyesterurethanes containing biodegradable segments and pendant cinnamamide groups. Biomacromolecules, 12, 235-241 (2011).

DOI: $10.1021 / \mathrm{bm} 1012162$

[13] Chamsaz E. A., Sun S., Maddipatla M. V. S. N., Joy A.: Photoresponsive polyesters by incorporation of alkoxyphenacyl or coumarin chromophores along the backbone. Photochemical and Photobiological Sciences, 13, 412-421 (2014). DOI: $10.1039 / \mathrm{c} 3 p p 50311 \mathrm{a}$

[14] Jiang J., Qi B., Lepage M., Zhao Y.: Polymer micelles stabilization on demand through reversible photo-crosslinking. Macromolecules, 40, 790-792 (2007).

DOI: $10.1021 / \mathrm{ma} 062493 \mathrm{j}$

[15] Kehrloesser D., Baumann R-P., Kim H. C., Hampp N.: Photochemistry of coumarin-functionalized $\mathrm{SiO}_{2}$ nanoparticles. Langmuir, 27, 4149-4155 (2011). DOI: $10.1021 / 1 \mathrm{a} 200238 \mathrm{y}$
[16] Sinkel C., Greiner A., Agarwal S.: Synthesis, characterization, and properties evaluation of methylcoumarin end-functionalized poly(methyl methacrylate) for photoinduced drug release. Macromolecules, 41, 3460-3467 (2008).

DOI: $10.1021 / \mathrm{ma} 702622 \mathrm{p}$

[17] Jin Q., Mitschang F., Agarwal S.: Biocompatible drug delivery system for photo-triggered controlled release of 5-fluorouracil. Biomacromolecules, 12, 3684-3691 (2011). DOI: $10.1021 / \mathrm{bm} 2009125$

[18] Schraub M., Kim H-C., Hampp N.: Photoinduced refractive index changes of 3-phenyl-coumarin containing polymers for ophthalmic applications. European Polymer Journal, 51, 21-27 (2014).

DOI: $10.1016 /$ j.eurpolymj.2013.11.014

[19] Ling J., Rong M. Z., Zhang M. Q.: Photo-stimulated selfhealing polyurethane containing dihydroxyl coumarin derivatives. Polymer, 53, 2691-2698 (2012).

DOI: $10.1016 /$ j.polymer.2012.04.016

[20] Ling J., Rong M. Z., Zhang M. Q.: Coumarin imparts repeated photochemical remendability to polyurethane. Journal of Materials Chemistry, 21, 18373-18380 (2011). DOI: $\underline{10.1039 / \mathrm{c} 1 \mathrm{jm} 13467 \mathrm{a}}$

[21] Chen Y., Jean C-S.: Polyethers containing coumarin dimer components in the main chain. II. Reversible photocleavage and photopolymerization. Journal of Applied Polymer Science, 64, 1759-1768 (1997).

DOI: $10.1002 /($ SICI) 1097-4628(19970531)64:9<1759 $\because$ AID-APP12>3.0.CO;2-T

[22] Zhao D., Ren B., Liu S., Liu X., Tong Z.: A novel photoreversible poly(ferrocenylsilane) with coumarin side group: Synthesis, characterization, and electrochemical activities. Chemical Communications, 2006, 779-781 (2006).

DOI: $10.1039 / \mathrm{b} 515413 \mathrm{~h}$

[23] Sinkel C., Greiner A., Agarwal S.: A polymeric drug depot based on 7-(2'-methacryloyloxyethoxy)-4-methylcoumarin copolymers for photoinduced release of 5fluorouracil designed for the treatment of secondary cataracts. Macromolecular Chemistry and Physics, 211, 1857-1867 (2010).

DOI: $10.1002 / \mathrm{macp} .201000206$

[24] Chung J. S., Kim H. S., Chae K. H.: Preparation of photo-crosslinkable polymers having coumarin side groups and their properties. Korea Polymer Journal, 3, 12-18 (1995).

[25] Nagata M., Yamamoto Y.: Photoreversible poly(ethylene glycol)s with pendent coumarin group and their hydrogels. Reactive and Functional Polymers, 68, 915-921 (2008). DOI: 10.1016/j.reactfunctpolym.2008.01.003

[26] Szycher M.: Szycher's handbook of polyurethanes. CRC Press, New York (2012).

[27] Oertel G.: Polyurethanes handbook. Hanser, Munich (1994). 